\title{
Creation of gear adaptive transmissions manufacture
}

\author{
Konstantin Ivanov ${ }^{1,2, *}$, Miroshnichenko M. S. ${ }^{3}$ \\ ${ }^{1}$ Chair "Control Systems for Aerospace Engineering", Almaty University of Power Engineering and Telecommunications, Almaty, Kazakhstan \\ ${ }^{2}$ Laboratory of Adaptive Mechanisms, Institute of Mechanics and Machine Science MON RK, Almaty, Kazakhstan \\ ${ }^{3}$ Chair of Management, Saint-Petersburg University of District Mechanics and Optics, Saint-Petersburg, Russia
}

\section{Email address:}

ivanovgreek@mail.ru (K. Ivanov), ritushka.92@mail.ru (Miroshnichenko M. S.)

\section{To cite this article:}

Konstantin Ivanov, Miroshnichenko M. S.. Creation of Gear Adaptive Transmissions Manufacture. American Journal of Mechanics and Applications. Special Issue: Adaptive Transmissions. Vol. 2, No. 6-1, 2014, pp. 21-24. doi: 10.11648/j.ajma.s.2014020601.14

\begin{abstract}
The project provides the organization of creation of machine-building manufacture of essentially new highly effective transmissions for motor industry on the basis of Machine-building factory (Saint- Petersburg, Almaty). Object of manufacture is the techniques created on the basis of science discovery by scientists and designers of university AUES and institute of Mechanics and Machine Science NAN RK after name academician U.A. Djoldasbekov (Kazakhstan). Creation of machine-building manufacture is based on use of the developed unique methods of synthesis and the discovery «Effect of force adaptation in the mechanics». Discovery materials are published in works of the international scientific forums, since 1995. Theoretical possibilities of discovery are realized by the gear mechanism with two degrees of freedom. Cogwheels are in constant gearing. At constant input power of the engine the target shaft of the mechanism rotates with a speed, inversely proportional variable loading without a gear change. Concrete application: a batch production of transmissions of cars for sale abroad.
\end{abstract}

Keywords: Business Plan, Adaptive Transmission, Manufacture, Profit

\section{Introduction}

Each businessman, beginning the activity, should represent clearly requirement for financial, material, labor and intellectual resources, sources of their reception, and also to be able to calculate accurately efficiency of use of resources in the course of enterprise work. In market economy businessmen cannot achieve stable success if will not plan accurately and effectively the activity, constantly to collect the information as about a condition of the target markets, position on them competitors, and about own prospects and possibilities.

The project provides the organization of creation of machine-building manufacture of essentially new highly effective transmissions for motor industry on the basis of Machine-building factory (Machine built Plant,Saint-Petersburg, Almaty). Object of manufacture is the techniques created on the basis of science discovery by scientists and designers of university AUES and institute of Mechanics and Machine Science NAN RK after name academician U.A. Djoldasbekov (Kazakhstan).

Creation of machine-building manufacture is based on use of the developed unique methods of synthesis and the discovery «Effect of force adaptation in the mechanics».
Discovery materials are published in works of the international scientific forums, since 1995 [1, 2 and 3]. Theoretical possibilities of discovery are realized by the gear mechanism with two degrees of freedom. Cogwheels are in constant gearing. At constant input power of the engine the target shaft of the mechanism rotates with a speed, inversely proportional variable loading without a gear change.

Concrete application: a batch production of transmissions of cars for sale abroad.

Analogues in world practice of motor industry are absent.

There are five patents of Kazakhstan: №3208, №11042, №12236, №14477, №17378, № 028847, the patent of Russia № 2398989, the patent of Germany № 202012101273.1 .

The project purpose - working out of the basic sections of business planning and definition of ways of effective creation of machine-building manufacture of transmissions, manufacturing and delivery to the interested enterprises of the patented highly effective industrial products which do not have analogues in world practice of mechanical engineering, reception of profit on sale of products. Projects for practical realization are created on the basis of developed by scientists AUES and IMMASH unique methods of synthesis of mechanisms, opening «Effect of power adaptation in the mechanic», original design workings out. 
In article the organization business plan is presented, the choice of forms and the methods of economic management necessary for effective activity of a small enterprise of Open Company «NPO Adaptive Transfer» on manufacture of boxes, their details and knots is carried out.

Firm «NPO Adaptive Transfer» and the market of machine-building manufacture are acting as the objects of research.

The developed business plan, and also the drawn conclusions and offers can be used for practical creation of firm.

Recently there were compact adaptive mechanical stepless adjustable transfers of Harries (1992) [1], Ivanov (2012) Germany[2] and Ivanov (2013) Houston [3]. Such transfer provides ideal conformity to variable load. The adaptive drive of car is now developed and bases of its research are created by Ivanov et al. (2013) [4]. Adaptive mechanical transfer is investigated in Ivanov's works [5, 6]. It is the elementary adjustable transfer as it contains only a wheelwork with constant cogging of toothed wheels (without the gear change). Transfer has small dimensions and weight.

Definability of motion takes place in the absence of friction account.

\section{Design of Adaptive Transmission}

The adaptive transmission [1] is presented on Fig. 1.

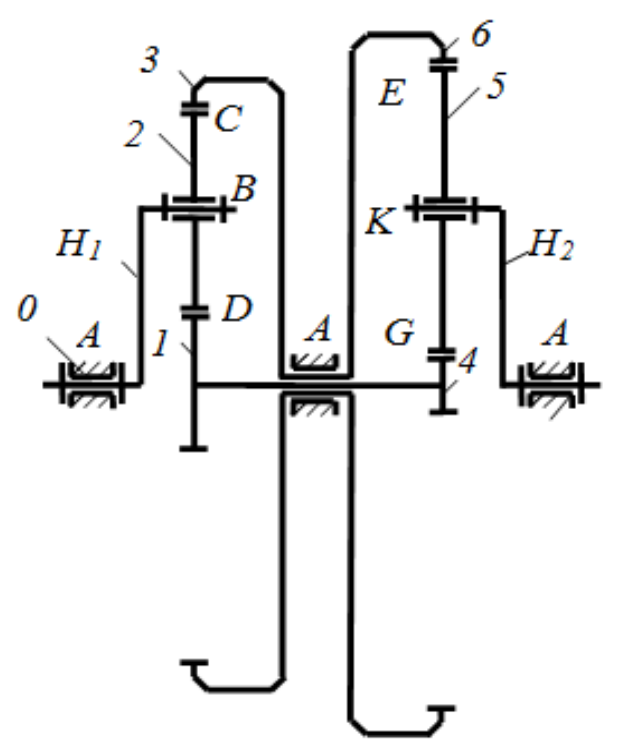

Figure 1. Gear adaptive transmission

The mechanism contains frame 0 , input carrier $H_{1}$, input satellite 2 , block of central toothed wheels with external teeth (solar wheels) $1-4$, block of central toothed wheels with internal teeth (ring wheels) $3-6$, output satellite 5 and output carrier $H_{2}$. Toothed wheels 4-1, 2, 3-6, 5 form the closed contour.

Adaptive-mechanical transfer represents the closed differential mechanism with two degrees of freedom.

The basic parts and quantity on 1 fabric:

0 :frame (1 piece),
$H_{1}$ : input carrier (1 piece),

$\mathrm{H}_{2}$ : output carrier (1 piece),

2:input satellite ( 3 pieces),

5:output satellite (2 pieces),

1, 4:solar wheels united in the block of wheels $1-4$ ( 1 piece),

3, 6:epicycle (ring) wheels united in the block of wheels 3-6 (1 piece), case (1 piece), cover (1 piece).

\section{Interconnection of Parameters of a Wheelwork}

Interconnection of parameters for the wheelwork with two degrees of freedom is defined by theorem: mobile closed contour in kinematic chain with two degrees of freedom under action of any way set superposed forces is in equilibrium $[2,3]$. Basic equations of parameters interconnection of wheelwork with two degrees of freedom have following form.

Sum of powers of internal forces is equal to null

$$
M_{1-4} \omega_{1}+M_{3-6} \omega_{3}=0
$$

Sum of powers of external forces is equal to null

$$
M_{H 1} \omega_{H 1}+M_{H 2} \omega_{H 2}=0
$$

From (2) follows

$$
\omega_{H 2}=\frac{M_{H 1} \omega_{H 1}}{M_{H 2}}
$$

Equation (3) defines effect of force adaptation: at constant input power $N_{H 1}=M_{H 1} \omega_{H 1}$ output angular speed $\omega_{H 2}$ is inverse proportional to external output resistance moment $M_{H 2}$. The effect of power adaptation characterizes the major property for machines with variable technological resistance ability independently and continuously to adapt for variable technological loading.

\section{Analysis of Manufacture of Transmissions}

Having analyzed the market of manufacture of transmissions, the basic competitors have been revealed are the countries-manufacturers Japan and USA. But, nevertheless, production made by Open Company «NPO Adaptive transfer» will be competitive, and to possess high potential in the market. As the investigated transmission unlike transmissions of competitors has following advantages: high quality of conformity to a variable mode of movement, high reliability and durability, simplicity of service and repair.

In the developed marketing plan the detailed analysis of consumers is resulted, formation of a price policy is considered, the cost price and the product price is defined, the organization of advertising activity and marketing researches are provided. The production plan and also legal maintenance of activity of firm is in details presented. The 
production plan represents cost price calculation in all respects accounting thanks to which subsequently it is possible to establish the product price. By the given calculations the transmission price will make 8000 rubles and it below the prices of competitors at least in 2 times.

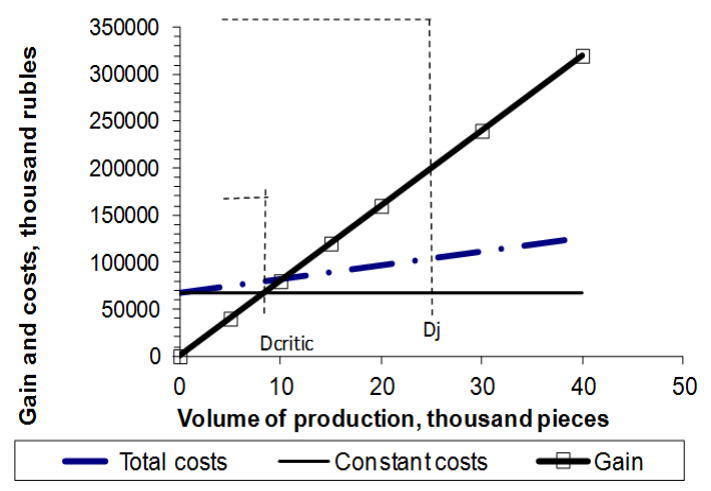

Figure 2. The break-even schedule

Possible investment risks have been revealed and ways of their overcoming are considered. The structure of expenses and incomes is presented. On the basis of these data the break-even schedule has been constructed on Fig. 2. The carried out analysis of break-even will help to keep an eye on borders of steady position of the enterprise. The given schedule (see more low) visually shows, that constant costs do not depend on a sales volume and make 67020 thousand rubles a year. Total costs (the sum of constants and variable costs) grow simultaneously with sale. The line of total receipts (gain) begins with a zero mark. The steepness of an inclination of total receipts depends on production price - the above the price, the above an inclination corner. For break-even maintenance (a covering of total costs) the enterprise should realize production for the sum a minimum of 81942 thousand rubles in a year. It is necessary to consider, that if a mid-annual sales volume more than a critical sales volume and profitability of production more standard, realization of such project means will be effective. Apparently from the break-even schedule all conditions are executed, therefore the carried out financial and economic analysis of the project allows to say that the presented project can be realized with high degree of efficiency.

Thanks to the spent researches following results have been received:

1 Competitive advantages of production of firm are shown

2 The structure of the organization of Open Company NPO «Adaptive transfer» has been developed.

3 The organizational plan and management structure is made, powers of employees are considered.

4 It is revealed, that use of the business plan of the project of opening of the organization of Open Company NPO «Adaptive transfer» will bring to the enterprise in 1 year essential profit.

The organization of manufacture of transmissions is the investment project focused on profit, thus, by the basic indicators of expediency of manufacture financial indicators are. Calculations have shown rather small time of recovery of outlay of the project - within 1 year.

As a result of the spent estimation of the investment project of the organization of manufacture of transmissions, their details and knots the conclusion is drawn on advantage of investment in the given project as it is economically expedient and effective (the conclusion is made on the basis of the resulted calculations in work Burov V.P. [7].

\section{Conclusion}

Thanks to the spent researches following results have been received:

1 Competitive advantages of production of firm of Open Company NPO «Adaptive transfer» in comparison with other enterprises - manufacturers of transmissions, their details and knots are shown. Existing transmissions are structurally difficult, have the big sizes and weight, quickly wear out, are not reliable in regulation, work as jerks, have high cost. The investigated transmission unlike transmissions of competitors has following advantages: absolute conformity to a variable mode of movement, high reliability and durability, constructive simplicity, small dimensions and weight, simplicity of service and repair.

2 The structure of the organization of Open Company NPO "Adaptive transfer» has been developed. The organizational plan and management structure is made, powers of employees are considered. In the developed marketing plan the detailed analysis of consumers, formation of a price policy, definition of the cost price and the product price, the organization of advertising activity and marketing researches is resulted. The production plan, and also legal maintenance of activity of firm is in details presented. It is revealed, that use of the business plan of the project of opening of the organization of Open Company NPO «Adaptive transfer» will bring to the enterprise in 1 year essential profit. Calculations have shown rather small time of recovery of outlay of the project - within 1 year.

Hence, the project is economically expedient and effective.

\section{References}

[1] Harries J. Power transmission system comprising two sets of epicyclic gears. Patent of Great Britain GB2238090 (A). 1991.

[2] Ivanov K.S. Almaty, KAZ - Owner of the registered sample. The name - Device of automatic and continuous change of a twisting moment - and changes of a corrected speed of output shaft depending on a tractive resistance. The deed on registration of the registered sample № 202012101 273.1. Day of Registration 02.05.2012. The German patent and firm establishment. Federal Republic Germany . 2012.

[3] Ivanov K.S. Theory of Continuously Variable Transmission (CVT) with Two Degrees of Freedom. Paradox of mechanics. Proceedings of the American Society of Engineers Mechanics (ASME) International Mechanical Engineering Congress \& Exposition (IMECE 2012). Houston, Texas: 2012. PP 543-562 
[4] Ivanov K.S. et al. Dynamic Synthesis of Adaptive Drive of Manipulator. 3rd IFToMM International Symposium on Robotics and Mechatronics (ISRM 2013). Singapore. 2013. PP $191-200$

[5] Ivanov K.S. Continuously Variable Transmission: adaptive gear stepless mechanical CVT. International Conference of Gears with Exibition. VDI Wissensforum GmbH. Technical University of Munich (TUM), Garching (near Munich). Germany .2013. PP 984 - 987.
[6] Ivanov K.S., Zhilisbaeva K.S. Paradox in the Mechanism Science. Mechanisms and Machine Science 19. New Trends in Educational Activity in the Field of Mechanism and Machine Theory. Springer. 2013. PP 129-136.

[7] Burov V.P. Biznes-plan of enterprise: Theory and practice. - M: Ecmo. 2000. P 176. 